\title{
A PROSPECTIVE STUDY ON VISUAL OUTCOME, IOP CONTROL AND COMPLICATIONS IN PATIENTS WITH LENS-INDUCED GLAUCOMA FOLLOWING MANUAL SICS IN A TERTIARY HEALTH CENTRE
}

\author{
Sewali Das ${ }^{1}$, Mritunjay Sharma ${ }^{2}$
}

${ }_{1}^{1}$ Assistant Professor, Department of Ophthalmology, Fakhruddin Ali Ahmed Medical College, Barpeta, Assam.

${ }^{2}$ Senior Resident, Department of Ophthalmology, Fakhruddin Ali Ahmed Medical College, Barpeta, Assam.

\begin{tabular}{l}
\hline ABSTRACT \\
BACKGROUND \\
Lens-induced glaucomas are a common occurrence in rural areas of India (Assam). A prospective study was done to analyse the \\
visual outcome, intraocular pressure control and complications in patients with lens-induced glaucoma following manual small \\
incision cataract surgery. \\
The objective of this study is to analyse the visual outcome, intraocular pressure control and complications in patients with \\
lens-induced glaucoma following manual SICS in a tertiary health centre.
\end{tabular}

\section{MATERIALS AND METHODS}

The present observational study was conducted in the Department of Ophthalmology, Fakhruddin Ali Ahmed Medical College and Hospital, Barpeta from September 2015 to August 2017. The study group included 68 patients clinically diagnosed as lens-induced glaucoma. Detailed history and thorough clinical examination of both eyes including visual acuity, Schiotz tonometry, slit-lamp biomicroscopy, fundus examination and gonioscopy were done. Cases were managed both medically and surgically. After control of IOP, manual small incision cataract surgery with PCIOL implantation with or without iridectomy was done under local (peribulbar) anaesthesia in all cases. Informed and written consents were taken. Data was recorded in a preformed proforma.

\section{RESULTS}

Out of 68 patients with LIG, majority of the patients were phacomorphic glaucoma $(60.2 \%)$ followed by phacolytic glaucoma (29.4\%). Most common age group affected was 51 - 60 years (35.2\%). Incidence of LIG was more among females (55.88\%) than males (44.11\%). Majority of cases numbering 28 (41.2\%) had IOP between $41-50 \mathrm{mmHg}$ at the time of presentation. While following operation after 3 months, most of the cases numbering $63(92.6 \%)$ had IOP less than $21 \mathrm{mmHg}$. At presentation, only 4 (5.9\%) cases had visual acuity between $6 / 6-6 / 18$ and 3 months following operation $34(50 \%)$ had visual acuity between $6 / 6$ 6/18. It was observed that out of 26 cases who presented within 5 days, 20 cases (76.9\%) had good vision, i.e. between 6/6 - 6/18, while in 14 cases who presented after 10 days none of them had good vision and amongst them 5 (35.7\%) had vision between $6 / 18-6 / 60$ and $9(64.3 \%)$ had poor vision $>6 / 60$. The common complications encountered were uveitis (7.4\%), PCR with vitreous loss (4.4\%), posterior capsular opacity (4.4\%), bullous keratopathy (2.9\%) and cystoid macular oedema (1.47\%).

\section{CONCLUSION}

It can be concluded that manual SICS is safe and effective in controlling IOP and attaining good functional visual recovery in the management of LIG. Surgical removal of lens with IOL implantation is the most effective treatment in a patient with LIG. Glaucoma secondary to hypermature cataract can be saved by prompt removal of the cataract. Earlier is the lens extraction, better is the visual and IOP outcome.

\section{KEYWORDS}

Lens-Induced Glaucoma, IOP, Visual Acuity, SICS.

HOW TO CITE THIS ARTICLE: Das S, Sharma M. A prospective study on visual outcome, IOP control and complications in patients with lens-induced glaucoma following manual SICS in a tertiary health centre. J. Evolution Med. Dent. Sci. 2017;6(93):6751-6754, DOI: $10.14260 /$ jemds/2017/1462

\section{BACKGROUND}

Lens-induced glaucoma is a secondary glaucoma, in which the crystalline lens is involved in the mechanism of intraocular pressure (IOP) increase. Glaucoma may occur in open angle or angle closure forms, and there are 4 distinct variants: phacolytic, phacomorphic, lens particle and phacoantigenic. Lens-Induced Glaucoma (LIG) is a common condition seen in

'Financial or Other Competing Interest': None.

Submission 21-11-2017, Peer Review 04-12-2017,

Acceptance 06-12-2017, Published 11-12-2017.

Corresponding Author:

Dr. Sewali Das,

Faculty Quarters,

Fakhruddin Ali Ahmed Medical College,

Joti Gaon, Barpeta-781301, Assam.

E-mail: dradas4@gmail.com

DOI: $10.14260 /$ jemds $/ 2017 / 1462$ patients with senile cataracts and it is one of the commonest cause of secondary glaucoma that requires an immediate attention and management to prevent blindness. ${ }^{1}$ Secondary glaucoma has been found in $10 \%$ of senile cortical cataract. ${ }^{2}$

Lens-related elevation in intraocular pressure (IOP) results from a variety of mechanisms such as lens dislocation, lens swelling (Intumescent cataract), inflammation due to phacoanaphylaxis and lens particle blocking the trabecular meshwork. Untreated increase in IOP damages the optic nerve mechanically, which inevitably leads to blindness. Due to large backlog of cataracts, poor health education, poor socio-economic status and fear of operation, LIG is more common in rural population. ${ }^{3}$

In most cases, the management of LIG is essentially surgical (ECCE with PCIOL implantation with or without iridectomy). ${ }^{4,5}$ However, intensive medical management is tried first to normalise IOP and inflammation. The prognosis 
for good post-operative visual recovery in these conditions remain guarded whatever be the mode of surgical intervention, unless diagnosed early and managed efficiently. ${ }^{6}$ Hence, the present study has been taken up to analyse the visual outcome, IOP control and complications following manual SICS in LIG patients.

\section{MATERIALS AND METHODS}

The present observational study was conducted in the Department of Ophthalmology, Fakhruddin Ali Ahmed Medical College and Hospital, Barpeta from September 2015 to August 2017. The study group included 68 patients clinically diagnosed as lens-induced glaucoma.

The inclusion criteria included the patients presented with pain, redness, watering of acute onset in addition to gradual progressive loss of vision in the affected eye along with clinical signs of circumciliary congestion, corneal oedema and cortical intumescent cataractous lens associated with raised IOP of $>21 \mathrm{mmHg}$.

Exclusion criteria included cases with primary open or narrow angle glaucoma, secondary glaucoma due to anterior and posterior segment pathologies associated with senile cataract, congenital cataract, secondary cataract and complicated cataract.

Detailed history and thorough clinical examination of both eyes including visual acuity, Schiotz tonometry, slit lamp biomicroscopy, fundus examination and gonioscopy were done. Biometry was done whenever possible for IOL power calculation. B-scan were also done in the affected eye in cases where fundus was not visible to rule out posterior segment pathology. Best corrected visual acuity was checked and recorded at the time of presentation, after surgery and at each follow-up visit (after one week, 6 weeks, 3 months) using Snellen's chart/ Landolt's C chart/ E chart.

Medical management consisting of topical steroids, antiglaucoma drugs, analgesics and in cases of pupillary block, a mydriatic was used. Dexamethasone eye drops was the preferred topical steroid instituted at hourly intervals which helped to bring down the inflammation. Local antibiotics like ciprofloxacin, moxifloxacin, ofloxacin and gatifloxacin were used in different combinations to make the conjunctival sac sterile. To reduce the IOP, Inj. Mannitol 20\%, $300 \mathrm{~mL}$ was given IV unless there were no contraindications for its use along with oral Acetazolamide $500 \mathrm{mg}$ stat followed by $250 \mathrm{mg} 6^{\text {th }}$ hourly. This was supplemented with topical beta blockers, preferably $0.5 \%$ Timolol maleate eye drops BID. After control of IOP, manual small incision cataract surgery with PCIOL implantation with or without iridectomy was done under local (peribulbar) anaesthesia. The patients were evaluated post-operatively for conjunctival congestion, corneal oedema, aqueous flare, cells and depth of anterior chamber, fundus, visual acuity and IOP.

Informed and written consents were taken. Data was recorded in a preformed proforma.

\section{RESULTS}

Out of 68 patients with LIG, our study showed highest number of phacomorphic glaucoma (60.2\%) followed by phacolytic glaucoma (29.4\%) (Table 1).

\begin{tabular}{|c|c|c|}
\hline Type of LIG & No. of Cases & Percentage (\%) \\
\hline Phacomorphic & 41 & $60.2 \%$ \\
\hline Phacolytic & 20 & $29.4 \%$ \\
\hline Lens particle & 03 & $4.4 \%$ \\
\hline Subluxated/ Dislocated & 04 & $5.8 \%$ \\
\hline Phacoanaphylactic & 0 & $0 \%$ \\
\hline \multicolumn{2}{|c|}{ Table 1. Showing Incidence of Type of LIG }
\end{tabular}

This study showed that the most common age group affected was $51-60$ years (35.2\%). Incidence followed by 61 - 70 years (26.4\%) and 41 - 50 years (20.5\%) (Table 2).

\begin{tabular}{|c|c|c|}
\hline Age Group (Year) & No. of Cases & Percentage (\%) \\
\hline $0-30$ & 02 & $2.94 \%$ \\
\hline $31-40$ & 03 & $4.4 \%$ \\
\hline $41-50$ & 14 & $20.5 \%$ \\
\hline $51-60$ & 24 & $35.2 \%$ \\
\hline $61-70$ & 18 & $26.4 \%$ \\
\hline $71-80$ & 05 & $7.35 \%$ \\
\hline $81-90$ & 02 & $2.94 \%$ \\
\hline \multicolumn{3}{|c|}{ Table 2. Age Distribution } \\
\hline
\end{tabular}

This study also showed a higher incidence of LIG in females (55.88\%) than males (44.11\%) (Table 3).

\begin{tabular}{|c|c|c|}
\hline Sex & No. of Cases & Percentage (\%) \\
\hline Male & 30 & $44.11 \%$ \\
\hline Female & 38 & $55.88 \%$ \\
\hline \multicolumn{3}{|c|}{ Table 3. Sex Distribution } \\
\hline
\end{tabular}

In our study, only $38.2 \%$ of the cases presented within 5 days of developing symptoms, $41.17 \%$ presented between 5 10 days and rest $20 \%$ presented beyond 10 days (Table 4).

\begin{tabular}{|c|c|c|}
\hline Duration & No. of Cases & Percentage (\%) \\
\hline$<5$ days & 26 & $38.2 \%$ \\
\hline $5-10$ days & 28 & $41.17 \%$ \\
\hline $11-15$ days & 8 & $11.76 \%$ \\
\hline$>15$ days & 6 & $8.82 \%$ \\
\hline \multicolumn{2}{|c|}{ Table 4. Duration of Symptoms } \\
\hline
\end{tabular}

Majority of cases $28(41.2 \%)$ had IOP between $41-50$ $\mathrm{mmHg}, 25(36.7 \%)$ had IOP between $31-40 \mathrm{mmHg}, 07$ $(10.3 \%)$ had IOP more than $50 \mathrm{mmHg}$ at the time of presentation.

Following operation, on day one only $2(2.9 \%)$ had IOP more than $50 \mathrm{mmHg}$ and only $6(8.8 \%)$ had IOP between 41 $50 \mathrm{mmHg}$ and majority of cases $28(41.2 \%)$ had IOP less than $21 \mathrm{mmHg}$; 24 (35.3\%) had IOP between 22 - $30 \mathrm{mmHg}$. After 3 months, most of the cases $63(92.6 \%)$ had IOP less than 21 mmHg (Table 5).

\begin{tabular}{|c|c|c|c|c|}
\hline \multirow{2}{*}{ IOP } & $\begin{array}{c}\text { At } \\
\text { Presentation } \\
\text { (\%) }\end{array}$ & $\begin{array}{c}\text { Following Operation } \\
\text { On Day } \\
\text { One (\%) }\end{array}$ & $\begin{array}{c}\text { After 01 } \\
\text { Week (\%) }\end{array}$ & $\begin{array}{c}\text { After 3 } \\
\text { Months } \\
\text { (\%) }\end{array}$ \\
\hline $0-21$ & 00 & $28(41.2 \%)$ & $58(85.3 \%)$ & $63(92.6 \%)$ \\
\hline $22-30$ & $08(11.7 \%)$ & $24(35.3 \%)$ & $08(11.7 \%)$ & $04(5.9 \%)$ \\
\hline $31-40$ & $25(36.7 \%)$ & $08(11.7 \%)$ & $02(2.9 \%)$ & $01(01.5 \%)$ \\
\hline $41-50$ & $28(41.2 \%)$ & $06(8.8 \%)$ & 00 & 00 \\
\hline$>50$ & $07(10.3 \%)$ & $02(2.9 \%)$ & 00 & 00 \\
\hline \multicolumn{5}{|c|}{ Table 5. IOP Status } \\
\hline
\end{tabular}


At presentation, only $4(5.9 \%)$ cases had visual acuity between 6/6 - 6/18, 37 (54.4\%) had visual acuity > 6/18 $3 / 60$, while $25(36.7 \%)$ had visual acuity $>3 / 60$ - perception of light. 2 (2.9\%) had no PL.

After 3 months following operation there was improvement in the visual acuity, $34(50 \%)$ had visual acuity between 6/6 - 6/18, 24 (35.3\%) had visual acuity > 6/18 $3 / 60,8$ (11.8\%) had visual acuity > 3/60 - PL (Table 6).

\begin{tabular}{|c|c|c|}
\hline Visual Acuity & $\begin{array}{c}\text { At Presentation } \\
\text { (\%) }\end{array}$ & $\begin{array}{c}\text { At 3 Months after } \\
\text { Operation (\%) }\end{array}$ \\
\hline $6 / 6-6 / 18$ & $04(5.9 \%)$ & $34(50 \%)$ \\
\hline$>6 / 18-6 / 60$ & $16(23.5 \%)$ & $17(25 \%)$ \\
\hline$>6 / 60-3 / 60$ & $21(30.9 \%)$ & $07(10.3 \%)$ \\
\hline $\begin{array}{c}>3 / 60-\text { hand } \\
\text { movement }\end{array}$ & $19(27.9 \%)$ & $05(7.4 \%)$ \\
\hline $\begin{array}{c}\text { Perception of } \\
\text { light }\end{array}$ & $06(8.8 \%)$ & $03(4.4 \%)$ \\
\hline $\begin{array}{c}\text { No perception of } \\
\text { light }\end{array}$ & $02(2.9 \%)$ & $02(2.9 \%)$ \\
\hline \multicolumn{3}{|c|}{ Table 6. Visual Acuity } \\
\hline \multicolumn{2}{|c|}{} \\
\hline
\end{tabular}

In our study, it was found that out of 19 patients who were less than 50 years, $57.9 \%$ achieved good visual acuity $(6 / 6-6 / 18)$ in comparison to $53 \%$ out of 49 patients who were more than 50 years (Table 7).

\begin{tabular}{|c|c|c|c|}
\hline Age & $\mathbf{6 / 6} \mathbf{- 6 / 1 8}$ & $>\mathbf{6 / 1 8}$ & No. of Patients \\
\hline$<50$ years & $11(57.9 \%)$ & $08(42.1 \%)$ & 19 \\
\hline$>50$ years & $26(53 \%)$ & $23(46.9 \%)$ & 49 \\
\hline & 37 & 31 & 68 \\
\hline \multicolumn{4}{|c|}{ Table 7. Age and Final BCVA } \\
\hline
\end{tabular}

It was observed that out of 26 cases who presented within 5 days $20(76.9 \%)$ had good vision, i.e. between $6 / 6$ $6 / 18,4(15.4 \%)$ had visual acuity between $6 / 18-6 / 60$, while only $2(7.7 \%)$ had poor vision, i.e. $>6 / 60$. Out of 28 cases who presented within 5 - 10 days 14 (50\%) had good BCVA, while $14(50 \%)$ had visual acuity $>6 / 18$. In 14 cases who presented after 10 days none of them had good vision, 5 (35.7\%) had vision between $6 / 18-6 / 60$ and $9(64.3 \%)$ had poor vision $>$ 6/60 (Table 8).

\begin{tabular}{|c|c|c|c|}
\hline \multirow{2}{*}{$\begin{array}{c}\text { Duration of } \\
\text { Symptoms }\end{array}$} & \multicolumn{3}{|c|}{ Final BCVA } \\
\cline { 2 - 4 } & $\mathbf{6 / 6 - 6 / 1 8}$ & $>\mathbf{6 / 1 8} \mathbf{- 6 / 6 0}$ & $>\mathbf{6 / 6 0}$ \\
\hline$<5$ days (26) & $20(76.9 \%)$ & $04(15.4 \%)$ & $02(7.7 \%)$ \\
\hline $5-10$ days (28) & $14(50 \%)$ & $08(28.5 \%)$ & $06(21.4 \%)$ \\
\hline$>10$ days (14) & 00 & $05(35.7 \%)$ & $09(64.3 \%)$ \\
\hline \multicolumn{3}{|c|}{ Table 8. Duration of Symptoms and Final BCVA } \\
(After 3 Months)
\end{tabular}

After 3 months, out of 8 cases who presented with IOP (22 - 30) mmHg, 6 (75\%) had good BCVA, remaining 2 (25\%) had poor vision. Out of 25 cases who presented with IOP (31 40) $\mathrm{mmHg}, 16$ (64\%) had good vision and 9 (36\%) had poor vision. In 35 cases that presented with IOP more than 40 mmHg, only 12 (34.3\%) had good BCVA, 23 (65.7\%) had poor BCVA (Table 9).

\begin{tabular}{|c|c|c|c|c|}
\hline \multirow{2}{*}{$\begin{array}{l}\text { IOP (In } \\
\text { mmHg) }\end{array}$} & \multicolumn{3}{|c|}{ Final BCVA } & \multirow{2}{*}{ Tota } \\
\hline & $6 / 6-6 / 18$ & $>6 / 18-6 / 60$ & $>6 / 60$ & \\
\hline $22-30$ & $06(75 \%)$ & $01(12.5 \%)$ & $01(12.5 \%)$ & 08 \\
\hline $31-40$ & $16(64 \%)$ & $05(20 \%)$ & $04(16 \%)$ & 25 \\
\hline$>40$ & $12(34.3 \%)$ & $11(31.4 \%)$ & $12(34.3 \%)$ & 35 \\
\hline & 34 & 17 & 17 & 68 \\
\hline
\end{tabular}

In our study, the common complications encountered following surgery were uveitis (7.4\%), bullous keratopathy (2.9\%), PCR with vitreous loss $(4.4 \%)$, posterior capsular opacity $(4.4 \%)$ and cystoid macular oedema (1.47\%) (Table 10).

\begin{tabular}{|c|c|}
\hline Common Complications & No. of Cases (\%) \\
\hline Uveitis & $05(7.4 \%)$ \\
\hline Bullous keratopathy & $02(2.9 \%)$ \\
\hline PCR with vitreous loss & $03(4.4 \%)$ \\
\hline Posterior capsular opacity & $03(4.4 \%)$ \\
\hline Cystoid macular oedema & $01(1.47 \%)$ \\
\hline \multicolumn{2}{|c|}{ Table 10. List of Common Complications } \\
\hline
\end{tabular}

\section{DISCUSSION}

Lens induced glaucoma is a common occurrence in India. Though phacomorphic and phacolytic glaucomas are clinically distinct entities, they have certain common factors, in that they are lens induced. They compromise the function of the optic nerve due to rise of intraocular pressure. Cataract surgery is curative in these cases and finally they uniformly share a guarded prognosis. ${ }^{7}$

In our study, it was noted that the most frequent type of LIG was Phacomorphic Glaucoma, which was found in 41 cases (60.2\%) followed by Phacolytic Glaucoma 20 (29.4\%). Similar occurrence was noted by Prajna et al ${ }^{6}$ (1996) and Pradhan et al 8 in 2001.

In our study, we have observed that the highest number of cases $24(35.2 \%)$ was in the age group of 51 - 60 years followed by $18(26.4 \%)$ in age group of $61-70$ years. In the study by Pradhan et al, ${ }^{8}$ LIG presented highest in the age group of $60-69$ years indicating that it is a condition of old age.

Females tend to have a higher risk of developing LIG compared to males with ratio of 1.26: 1 in our study. Pradhan et $\mathrm{al}^{8}$ has reported female-to-male ratio of 1.7: 01. Similar results were reported by Rijal AP et al. ${ }^{9}$

Majority of cases numbering 26 (38.2\%) presented within 5 days of developing symptoms and 28 cases (41.2\%) presented between 5 - 10 days of developing symptoms and rest $14(20.6 \%)$ presented after 10 days in our study. This correlates with the study of Raghunadan et al,10 in which $16.0 \%$ presented in $<48 \mathrm{hrs}$., $44.0 \%$ in $3-6$ days and $40.0 \%$ in $>$ a week. The study of R. Ramakrishnan et al ${ }^{11}$ showed a figure of $84.0 \%$ in $<10$ days and $16.0 \%$ in $>10$ days. We observed similar findings in our study. Most of the patients who presented with LIG were from rural and semi-urban areas and of poor socio-economic background and many of them took local indigenous treatment for redness and pain in eyes and reported to eye hospital only when the symptoms became worse. Illiteracy, ignorance, acceptance of poor vision as a part of ageing and fear of operation might be one of the important reason for late presentation in our study. 
In this study, it was observed that out of 26 cases who presented within 5 days 20 cases (76.9\%) had good vision, i.e. between $6 / 6$ - 6/18. Out of 28 cases who presented between 5 - 10 days, 14 (50\%) had good BCVA. In 14 cases who presented after 10 days, none of them had good vision, 5 (35.7\%) had vision between 6/18 - 6/60 and 9 (64.3\%) had poor vision $>6 / 60$ (Table 8).

So a significant risk of poor visual acuity was found when the duration between the onset of symptom and presentation in our OPD was more than 5 days. Similar observation was made by Prajna et al, ${ }^{6}$ where a significant risk of poor visual acuity was found when the duration between the onset of pain and surgery exceeded 5 days.

It was observed that out of 19 patients who were less than 50 years, $57.9 \%$ achieved good visual acuity (6/6 $6 / 18$ ) in comparison to $53 \%$ out of 49 patients who were more than 50 years (Table 7).

Out of 68 preoperative cases there were no cases that had IOP between 0 - $21 \mathrm{mmHg} ;(11.7 \%)$ cases between 22 - 30 $\mathrm{mmHg}, 25(36.7 \%)$ cases between $31-40 \mathrm{mmHg}$ and 35 (51.5\%) cases had more than $40 \mathrm{mmHg}$. However, postoperatively after 3 months, $63(92.6 \%)$ cases had IOP between 0 - $21 \mathrm{mmHg}, 04$ (5.9\%) had IOP between $22-30$ $\mathrm{mmHg}, 01(01.5 \%)$ had IOP between $31-40 \mathrm{mmHg}$. No postoperative case had IOP $>40 \mathrm{mmHg}$.

Out of 8 cases who presented with IOP less than 31 mmHg, 6 cases (75\%) had a good BCVA at the end of 3 months; remaining 2 cases (25\%) had poor vision. In 25 cases that presented with IOP between $31-40 \mathrm{mmHg} 16$ cases $(64 \%)$ had good visual acuity, while 5 cases $(20 \%)$ had fairly useful vision and 4 cases (16\%) had poor vision. Out of the 35 cases that presented with IOP more than $40 \mathrm{mmHg}, 12$ cases (34.3\%) had good vision, 11 cases (31.4\%) had fairly useful vision and remaining 12 cases (34.3\%) had poor vision (Table 9). Prajna et $\mathrm{al}^{6}$ also found similar outcome.

In our study, the common complications encountered following surgery were uveitis (7.4\%), bullous keratopathy (2.9\%), PCR with vitreous loss $(4.4 \%)$, posterior capsular opacity (4.4\%) and cystoid macular oedema (1.47\%). Uveitis and CME were managed with frequent and stronger topical steroid and systemic steroid. PCO were treated with YAG capsulotomy. In a study by Mohinder Singh, 12 post-operative complications encountered were post-operative uveitis, inflammatory deposits on the lens implant surface and striate keratopathy. Other complications were Hyphaema, Iris Implant adhesions and Pupillary block glaucoma.

Delayed reporting for treatment leads to serious complications like lens induced glaucoma causing irreversible visual loss. LIG is a condition to reckon with in our ophthalmic patients, especially ours being a rural area. The final visual acuity was related more to the duration of attack than to the type of surgery. Visual prognosis is poor if there was a delay in seeking treatment.

\section{CONCLUSION}

In a developing country like India, manual SICS has gained more popularity over phacoemulsification owing to its shorter learning curve and being inexpensive.

From our study, it can be concluded that manual SICS is safe and effective in controlling IOP and attaining good functional visual recovery in the management of LIG. Surgical removal of lens with IOL implantation is the most effective treatment in a patient with LIG. Glaucoma secondary to hypermature cataract can be saved by prompt removal of the cataract. Earlier is the lens extraction, better is the visual and IOP outcome.

In spite of availability of surgical facilities, still many people are becoming blind due to lack of awareness about significance of early management. Illiteracy, older people and rural population are the worst affected. So, there is a greater need to impart health education to the public about the importance of timely surgery for better visual outcome.

\section{ACKNOWLEDGEMENTS}

The authors acknowledge the support and assistance provided by Ratna Devi Nath and Hemanga Dutta without which the paper would not have been completed within a limited timeframe.

\section{REFERENCES}

[1] Fletcher AE, Donoghue M, Devavaram J, et al. Low uptake of eye services in rural India: a challenge for programs of blindness prevention. Arch Ophthalmol 1999;117(10):1393-9.

[2] Nischal K, Pearson A. Glaucoma. In: Kanski JK, Bowling B. eds. Clinical ophthalmology: a systematic approach. 7th edn. London: Elsevier 2011: p. 311.

[3] PrasadRao SVS. A clinical study on visual outcome \& visual prognostic factors of lens induced glaucoma. Journal of Evolution of Medical and Dental Sciences 2015;4(40):6960-6.

[4] Epstein DI. Diagnosis and management of lensinduced glaucoma. Ophthalmology 1982;89(3):22730.

[5] Epstein DI. Lens induced open angle glaucoma. In: Ritch R, Sheilds MB. eds. The secondary glaucoma. St. Louis: CV Mosby 1982:121-30.

[6] Prajna NV, Ramakrishnan R, Krishnadas R, et al. Lens induced glaucomas - visual results and risk factors for final visual acuity. Ind J Ophthalmol 1996;44(3):14955.

[7] Richter CU. Lens induced open angle glaucoma. In: Rich R, Shields B, Krupin T. eds. The glaucomas. Vol 2. $2^{\text {nd }}$ edn. Mosby 1996:1023-30.

[8] Pradhan D, Hennig A, Kumar J, et al. A prospective study of 413 cases of lens induced glaucoma in Nepal. Ind J Ophthalmol 2001;49(2):103-7.

[9] Rijal AP, Karki DB. Visual outcome and IOP control after cataract surgery in lens induced glaucomas. Kathmandu University Medical Journal 2006;4(13): 30-3.

[10] Kothari R, Tathe S, Gogri P, et al. Lens-induced glaucoma: the need to spread awareness about early management of cataract among rural population. Article ID 581727, ISRN Ophthalmology 2013;2013: p. 3.

[11] Ramakrishanan R, Maheshwari D, Kader MA, et al. Visual prognosis, intraocular pressure control and complications in phacomorphic glaucoma following manual small incision cataract surgery. Indian J Ophthalmol 2010;58(4):303-6.

[12] Singh M, Al-Arrayyed H, Krishnan R. Intraocular lens implantation in phacomorphic glaucoma. Bahrain Medical Bulletin 2002;24(3):88-90. 